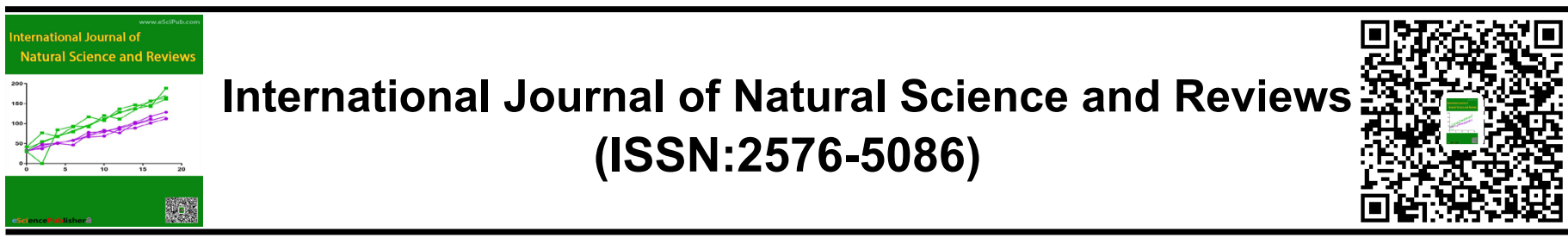

\title{
Design and realization of fault simulation software for cooling water system of marine diesel engine
}

\author{
LI Bao-yue ${ }^{1}$, JIANG Guo-he ${ }^{1}$, CHEN Bi-we ${ }^{1}$ \\ ${ }^{1}$ Merchant Maritime College, Shanghai Maritime University, Shanghai 201306, China.
}

\begin{abstract}
Aiming at the problems of high training cost and high safety risk in the training of marine diesel engine cooling water system

*Correspondence to Author: operators, a mathematical model is established based on LI Bao-yue

the technical parameters, working conditions and measured data of MTU20V956TB92 marine diesel engine cooling water 201306, China.

system. The simulation software of diesel engine cooling water system faults is developed by using Visual Studio 2012 platform, which realizes from mathematical model to code. Conversion to simulate the working state of ship cooling water system in normal operation and failure. The results show that the system can accurately simulate the normal operation and fault state of the cooling water system, and improve the actual ability of the trainers to respond to the fault of the ship cooling water system.

How to cite this article:

LI Bao-yue, JIANG Guo-he, CHEN $\mathrm{Bi}$-wen. Design and realization of fault simulation software for cooling water system of marine

Keywords: Marine diesel engine; Cooling water system; Fault diesel engine. International Journsimulation

al of Natural Science and Reviews, 2019; 4:11

\section{eScî̀Pub}

eSciPub LLC, Houston, TX USA.

Website: https://escipub.com/
\end{abstract}




\section{Introduction}

The ship simulation technology has been studied in foreign countries since the 1980s, and a marine engine simulation device has been developed to replace the physical marine engine for the relevant personnel to learn and use. Domestic simulation technology started late, and the technology is relatively immature ${ }^{[1]}$. In the process of combustion of fuel, about $1 / 3$ of the heat of marine diesel engine needs to be emitted by itself. In order to ensure that the diesel engine is at a good working temperature, cooling water is needed to cool the key heat dissipation components of the ship. The main functions of the marine cooling water system are to keep the temperature of the heated parts in a reasonable working range to ensure their working strength, to keep the temperature difference between the heated parts inside and outside to reduce their thermal stress, to keep the piston and cylinder liner in a proper gap and to keep the lubricating film on the cylinder wall in a normal working temperature. Therefore, it is partic- ularly important to ensure the stable and normal operation of the ship cooling system in the engine. The good working state of the cooling water system can ensure the stable operation of the ship, so the simulation of the cooling water system fault has important practical significance for the training of relevant staff. In addition, fault simulation software also has many advantages such as reducing workload of staff, reducing training costs, fault visualization, etc. ${ }^{[2]}[3]$.

\section{Mathematical Model of Cooling Water Sys- tem for Marine Diesel Engine}

In the simulation system, the reasonable construction of mathematical model is a very important part, which is the basis of system design and implementation. We simulate the data generated by each device through modeling method $^{[4]}$.

In this paper, MTU20V956TB92 is taken as the research object. It is a four-stroke direct-injection water-cooled turbocharged diesel engine with medium $V$ configuration. Its basic parameters are as follows.

Table 1-1 Basic Parameters of Diesel Engines

\begin{tabular}{ccc}
\hline Serial number & Name & parameter \\
\hline 1 & Model & MTU20V956TB92 \\
2 & Cylinder number & 20 \\
3 & Cylinder diameter & 230 \\
& $(\mathrm{~mm})$ & \\
4 & Rated power $(\mathrm{kw})$ & 4380 \\
5 & rotation rate & 1500 \\
& $(\mathrm{r} / \mathrm{min})$ & \\
\hline
\end{tabular}

2.1 Mathematical Model of Cooling Lubricating Oil System

The cooling of lubricating oil is mainly accomplished by countercurrent heat transfer between fresh water and lubricating oil in the cooler. The temperature of lubricating oil is kept in a reasonable temperature range to ensure its good lubricity and viscosity, thus maintaining the working 
state of diesel engine.

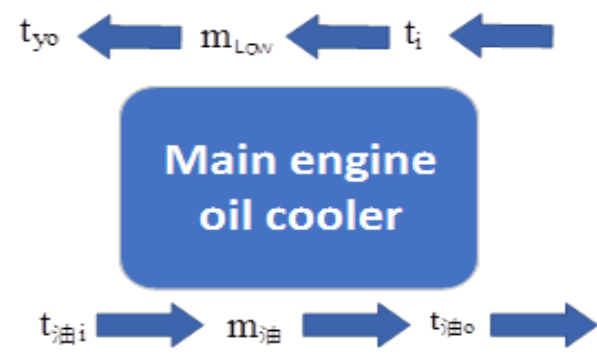

Figure 1-1 Heat transfer diagram of cooling lubricating oil system

By heat transfer equation:

$$
\frac{d t_{y o}}{d \tau}=\frac{1}{W_{3}}\left[\frac{1}{R_{1}} \Delta T_{1}-m_{l o w} c_{l}\left(t_{l o}-t_{i}\right)\right]
$$

$t_{i}$ :Temperature of Low Temperature Freshwater Intake Cooler; ${ }^{t}{ }$ :Temperature of low temperature fresh water outlet cooler; $m_{\text {low }}$ :Mass Flow of Low Temperature Freshwater; $W_{3}$ : Thermal Capacity of Freshwater Side at Low Temperature; $R_{1}$ : Heat Transfer and Thermal Resistance of Main Engine Lubricating Oil Cooler; $\Delta T_{1}$ : Average Temperature Difference of Lubricating Oil

$$
\Delta T_{1}=\frac{\left(t_{\text {油 } i}+t_{i}\right)-\left(t_{\text {油o }}+t_{y o}\right)}{\ln \frac{t_{\text {油 } i}-t_{y o}}{t_{\text {油o }}-t_{i}}}
$$

$t_{\text {油 } i}$ : Lubricating oil inlet cooler temperature; $t_{\text {油o }}$ : $t_{i}$ : Temperature of Low Temperature Freshwater 滑油出冷却器温度; $t_{y o}$ : 低温淡水出冷却器温度; Intake Cooler. From top to bottom:

$$
\frac{d t_{\text {油o }}}{d \tau}=\frac{1}{W_{4}}\left[m_{\text {油 }} c_{\text {油 }}\left(t_{\text {油 } i}-t_{\text {油o }}\right)-\frac{1}{R_{1}} \Delta T_{1}\right]
$$

$W_{4}$ : Thermal Capacity of Lubricating Oil Side;

accumulated heat on the side of the lubricating $c_{\text {油: Specific heat of lubricating oil. }}$ oil minus the heat transferred to the cooling waThe formula is expressed as the change of the ter in unit time. (1-1), (1-2), (1-3) are the heat 
transfer mathematical models of the main engine lubricating oil cooler.

\subsection{Mathematical Model of Cylinder Liner Cooling Water for Main Engine}

Diesel engine is one of the main cooling parts of cooling water system. The cylinder liner of diesel engine is cooled by cooling water to keep its working temperature within a certain range, so as to keep the diesel engine in a sustainable working state. Figure 1-2 shows the heat transfer schematic diagram of the cylinder liner of a diesel engine, in which the excess heat generated by the combustion of the diesel engine is transferred to the cylinder liner. The difference between this part of heat and the heat carried by the cooling water is the heat change of the diesel engine [5]

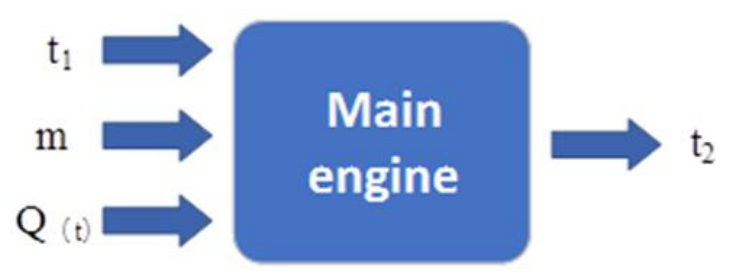

Figure 1-2 Diagram of Heat Transfer in Cylinder Liner of Diesel Engine

$$
W \frac{d t_{2}}{d \tau}=Q_{\text {in }}-Q_{\text {out }}=Q(t)-m c\left(t_{2}-t_{1}\right)
$$

$W$ : Total Heat Capacity of Cooling Water and Cylinder Liner in Cylinder Liner, $W=M c+M_{0} c_{0}$; $M$ : Cooling water in cylinder liner; $M_{0}$ : Quality of Cylinder Liner; $c$ : Specific heat of cooling water; $c_{0}$ : Specific heat of cylinder liner; $m$ : Mass Flow Rate of Cylinder Liner Cooling Water; $t_{1}$ : Inlet temperature of main engine cylinder

$$
Q(t)=\frac{d^{*} P^{*} b_{e} * \xi}{3600}
$$

$P$ : Host power, unit: $K w ; b_{e}$ : Fuel consumption rate, unit: $K g / K w h ; \xi$ : Low calorific value of liner cooling water; $t_{2}$ : Outlet temperature of main engine cylinder liner cooling water; $Q(t)$ : Heat transfer from diesel engine combustion to cooling water per unit time.

This paper assumes that the cooling water can take away the heat in the cylinder of a diesel engine in a fixed proportion $d(d=20 \%)$ is:

$$
\frac{d t_{2}}{d \tau}=\frac{d^{*} P^{*} b_{e} * \xi}{3600 W}-\frac{m c}{W} t_{2}+\frac{m c}{W} t_{1}
$$

Formula (1-6) is a simplified thermodynamic mathematical model for the cooling of the main engine cylinder liner.

\subsection{Mathematical Model of Visceral Block-} age in Seadoor Filter

The submarine door filter is mainly used to block some dirt, marine organisms and other substances in the sea water, so as to avoid blocking the passage. Therefore, when modeling the filter, the filter should be regarded as a throttle original ${ }^{[6]}$. When the fluid flows through the throttle original, it will produce corresponding lo- 
cal resistance loss, that is:

$$
h_{j}=\zeta \frac{U^{2}}{2 g}
$$

$\mathrm{U}$ : Average Velocity of Seawater in Pipeline $(\mathrm{m} /$ $\mathrm{s}) ; \xi$ : resistance coefficient. The inlet and outlet pressure of the filter is calculated by Bernoulli equation.

$$
Z_{1}+\frac{P_{1}}{\rho g}+\frac{U_{1}^{2}}{2 g}=Z_{2}+\frac{P_{2}}{\rho g}+\frac{U_{2}^{2}}{2 g}+h_{j}
$$

Among them: the height of section position $Z_{1}$ and $Z_{2}$, the pressure of section position $P_{1}$ and section position $\mathrm{P}_{2}$, respectively; $\rho_{\text {is }}$ the density of sea water.

$$
U=\frac{4 Q_{12}}{\pi d^{2}}
$$

Substitute (1-7) and (1-8) into (1-9) and take into account $Z_{1}=Z_{2}, U_{1}=U_{2}$, Then the following form-

$$
P_{1}-P_{2}=\frac{8 \rho \zeta Q^{2}}{\pi^{2} d^{4}}
$$

\subsection{Mathematical Model of Water Pump}

Water pump is an important part of marine diesel engine cooling system. The normal operati-

$$
H=K_{0}+K_{1} Q+K_{2} Q^{2}
$$

$K_{0}$ : Pressure Head at No Load; $K_{1}$ : Dynamic Pressure Loss Coefficient of Pump; $K_{2}$ : Pressure loss constant of pump itself; $H$ : Pump lift unit: $m^{3} / s\left(K_{0}, K_{1}, K_{2}\right.$ is the fixed parameter

$$
N_{s}=\frac{N Q^{0.5}}{H^{0.75}}
$$

$\mathrm{N}$ : rotation rate, unit: rpm;

3. Implementation of the system

\subsection{Main Structure Design of the System}

Through drawing software to draw the water
The relationship between fluid velocity $Q$ and flow rate $U$ in pipeline can be expressed by the following formula:

ula can be obtained:

on of water pump is an important guarantee of the system. The characteristic equation of the pump is as follows:

index of the pump)

When choosing the mathematical model, the pumps are classified according to the specific speed, which is defined as:

pump, pipeline, button, valve, instrument and other controls of cooling water system, and use 
LI Bao-yue. et al., IJNSR, 2019; 4:11

component technology to increase the reusability of code to meet the design requirements of the system. The system is mainly composed of seawater system, freshwater system and fault simulation system. Each subsystem has the functions to be realized by each subsystem.
Each function needs to establish links with the database, read data from each other, and then appear on the system interface. The structure flow chart of the system is shown in Fig. 2-3, and the arrangement of the freshwater system in the design process is shown in Fig. 2-2.

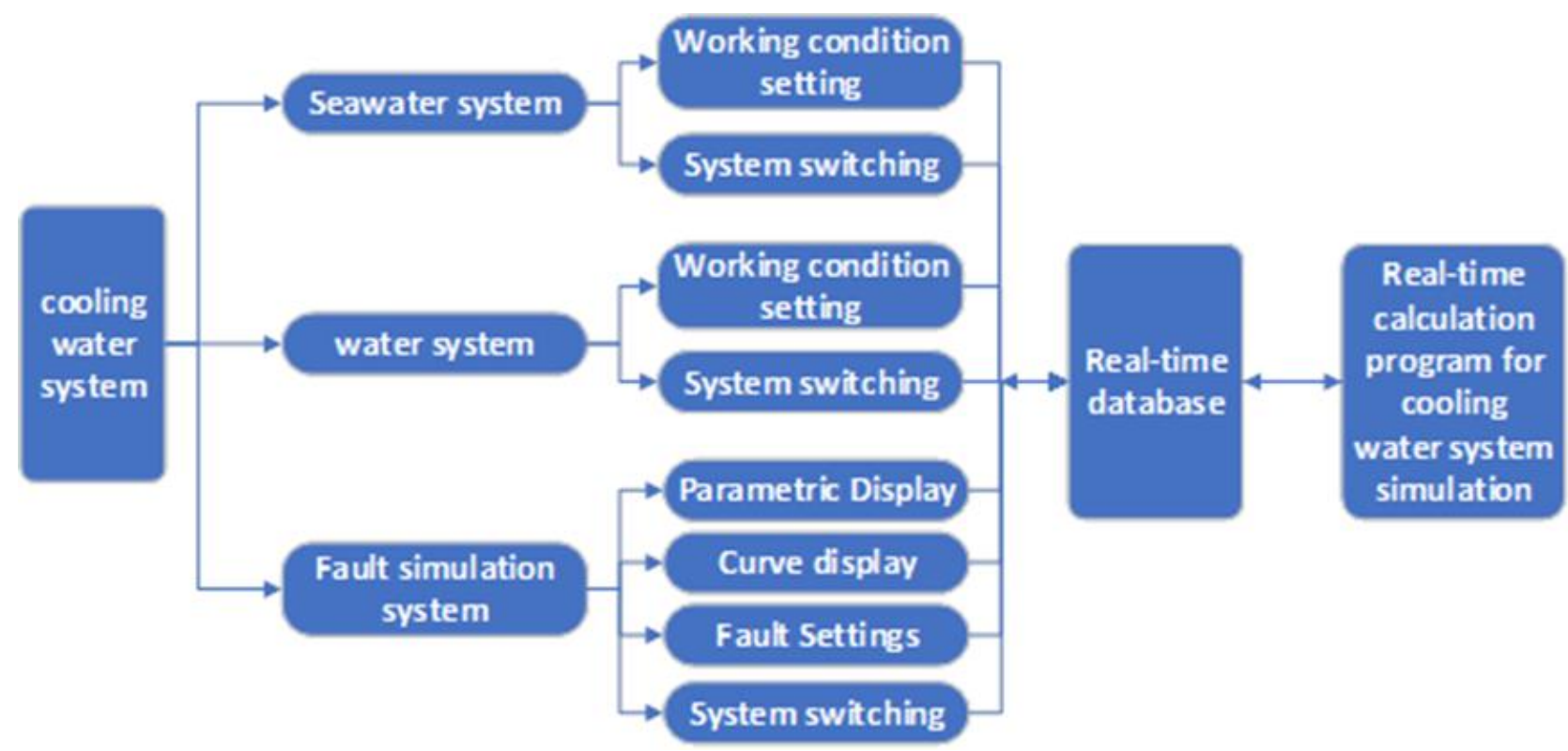

Figure 2-1 Schematic diagram of cooling water system structure

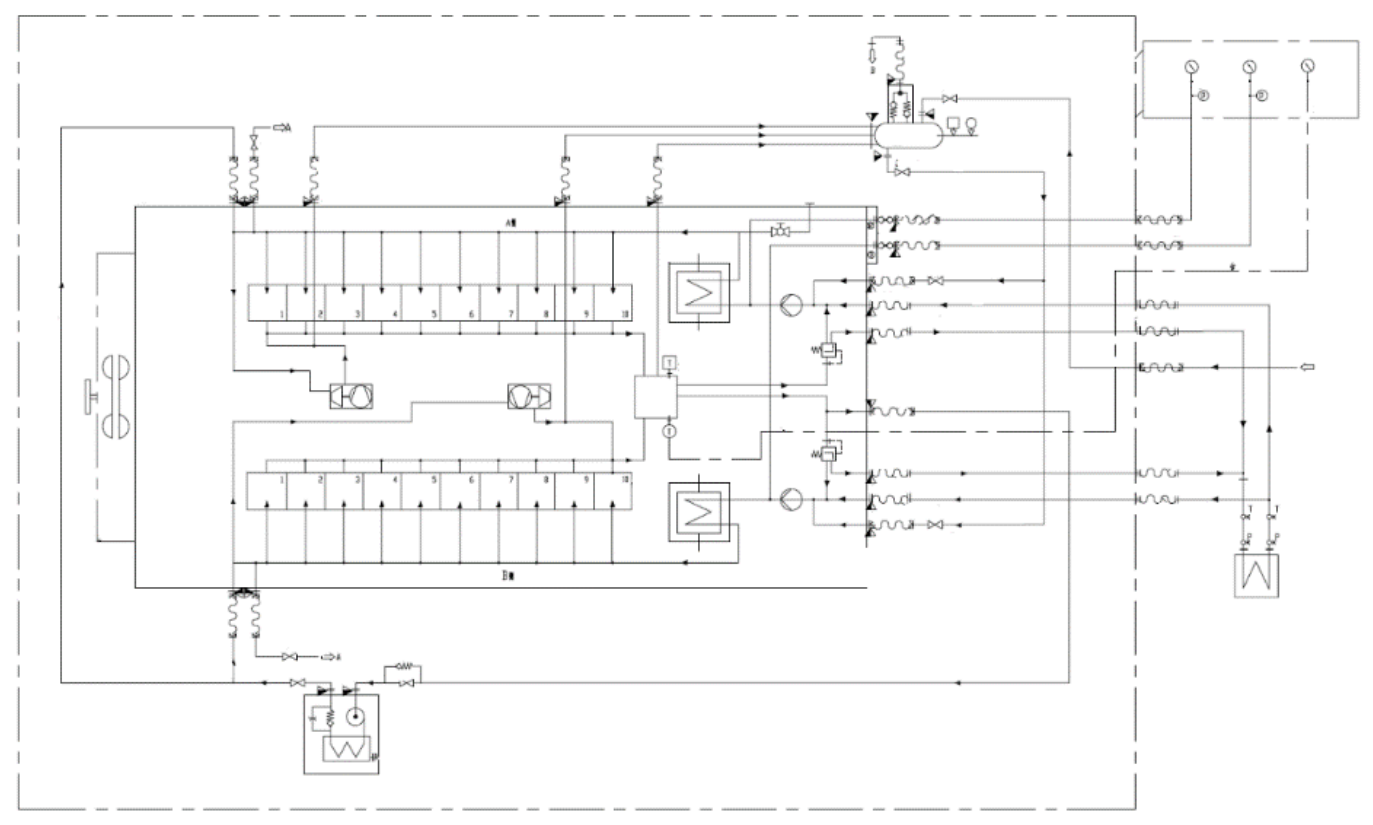

Figure 2-2 Freshwater Interface Layout of the System

\subsection{Data linkage in the system}

In the system, the relevant parameters of each component are constantly changing, and the parameters of other parts of the system will change after the failure of one part. After establishing the correct mathematical model, the system runs according to the given conditions, the results of the system are judged according to 
LI Bao-yue. et al., IJNSR, 2019; 4:11

the logical control model, and finally the real- water system and other systems. The system time parameters of the mathematical model are uses PID control [8] [9]. Figure 2-4 shows the displayed ${ }^{[7]}$. Figure 2-3 shows the block dia- block diagram of PID control algorithm. gram of information exchange between cooling

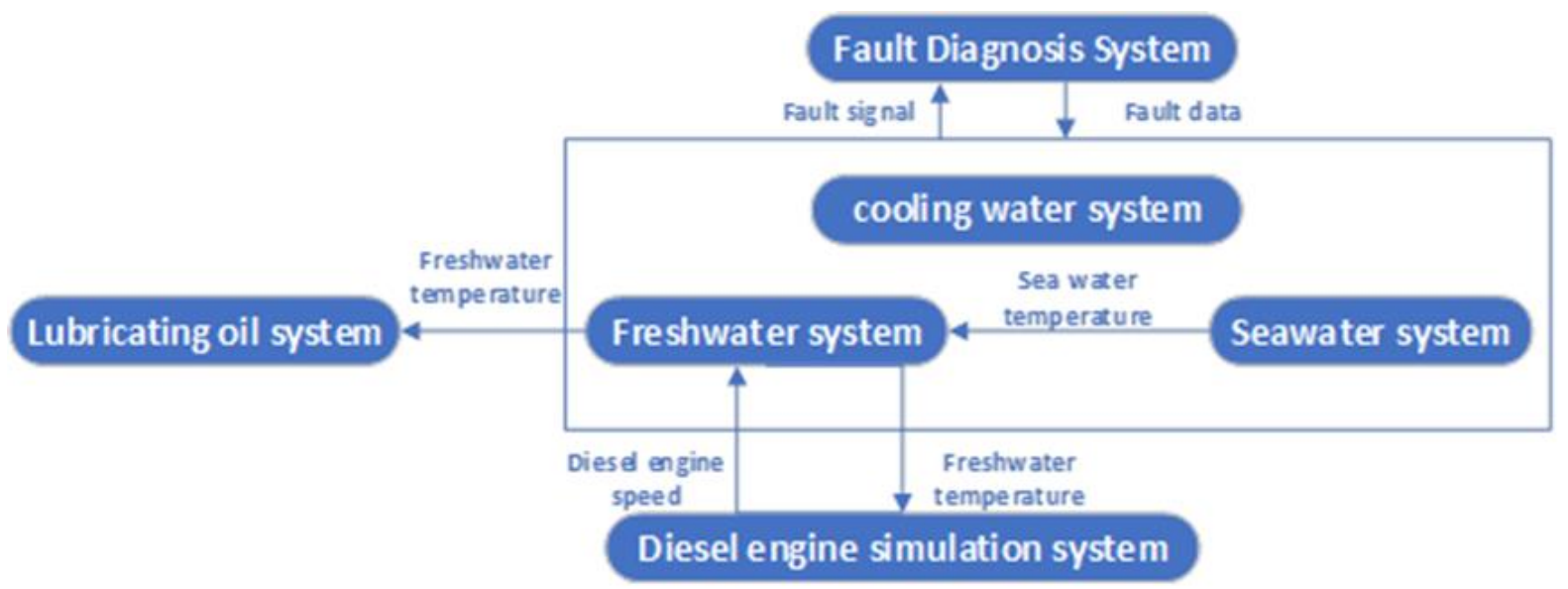

Figure 2-3 Information Interaction between Cooling Water System and Other Systems

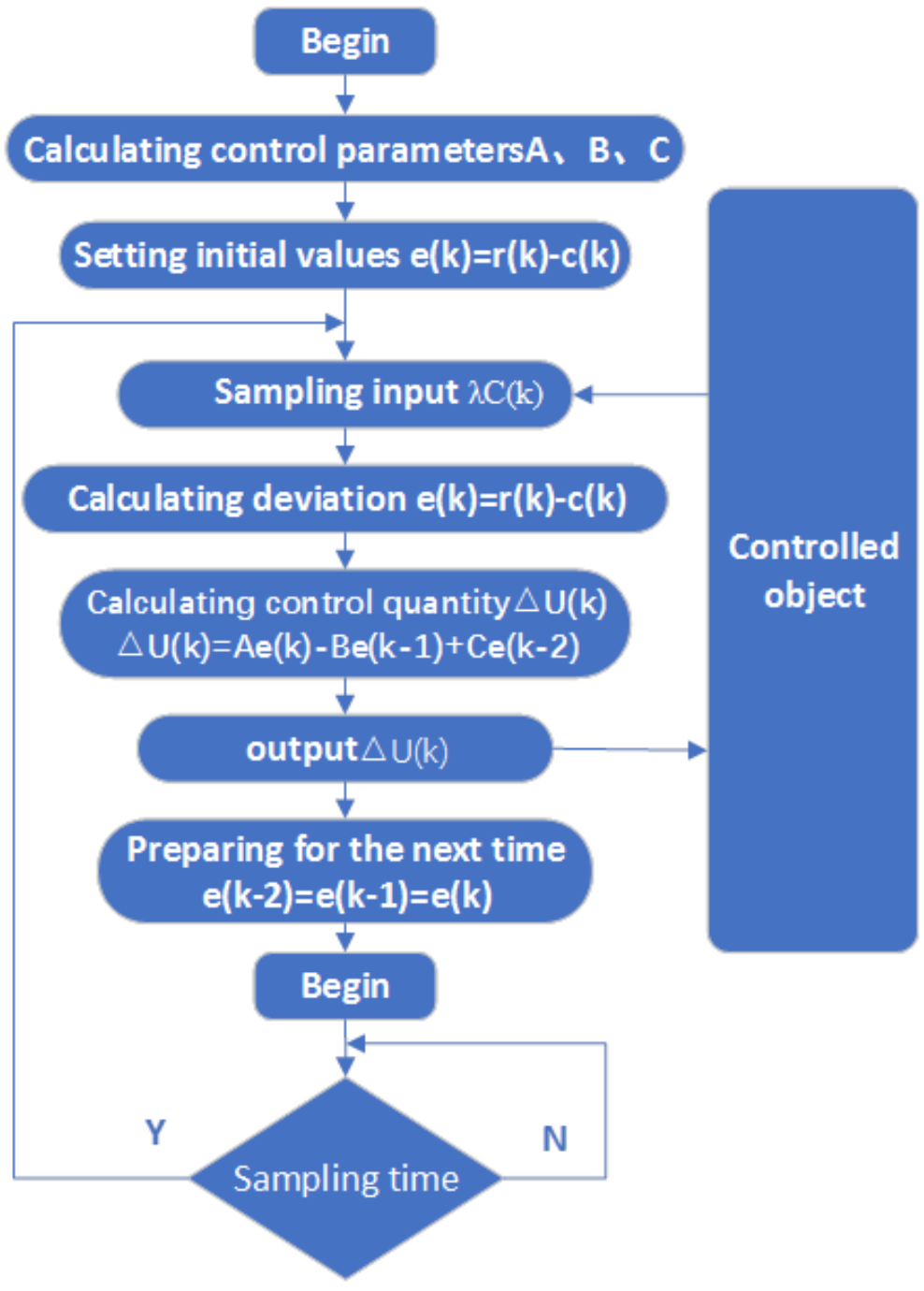

Figure 2-4 Block diagram of PID control algorithm 


\subsection{Design of database in fault simulation}

In this system, the trainees can simulate the faults by injecting the faults into the system interface. In the design process, I have edited and arranged the specific parameters corresponding to the faults in an Excel table. After the faults are injected, the data can be invoked. The current fault parameters can be displayed in the system interface to simulate the faults of the cooling water system.

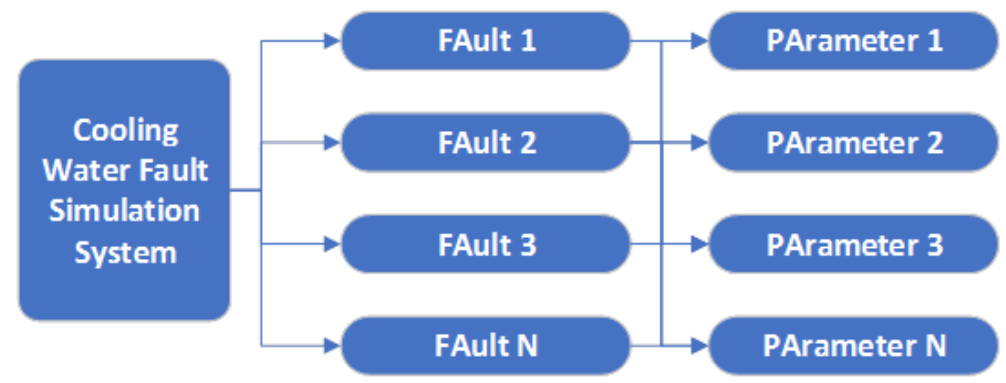

Figure 2-4 Structure of Excel database

\section{Examples of System Fault Simulation}

There are many kinds of faults in this system, and the system can be changed slightly according to the need. The following two examples are the abrasion of seawater pump and the blockage of submarine door to show the effect of the system after completion.

\subsection{Wear Failure of Seawater Pump}

Figure 3-1 shows the normal wear failure display interface of seawater pump. It can be seen from the chart that the pressure of the return pump is stable at about $0.16 \mathrm{MPa}$ and the flowrate of the pump is about $50 \mathrm{~m} 3 / \mathrm{h}$. After common wear and tear failure, the pressure and flow rate of the sea water pump begin to decrease. After a period of time, the flow rate of the pump drops to about $39 \mathrm{~m} 3 / \mathrm{h}$ and the pressure of the pump drops to about $0.14 \mathrm{MPa}$. If there is no other operation, the fault will continue, and because of the correlation of mathematical models [10], if the oil cooler is selected as the measuring point, the cooling water temperature will increase. If other relevant measuring points are selected, the data of other measuring points will change accordingly.

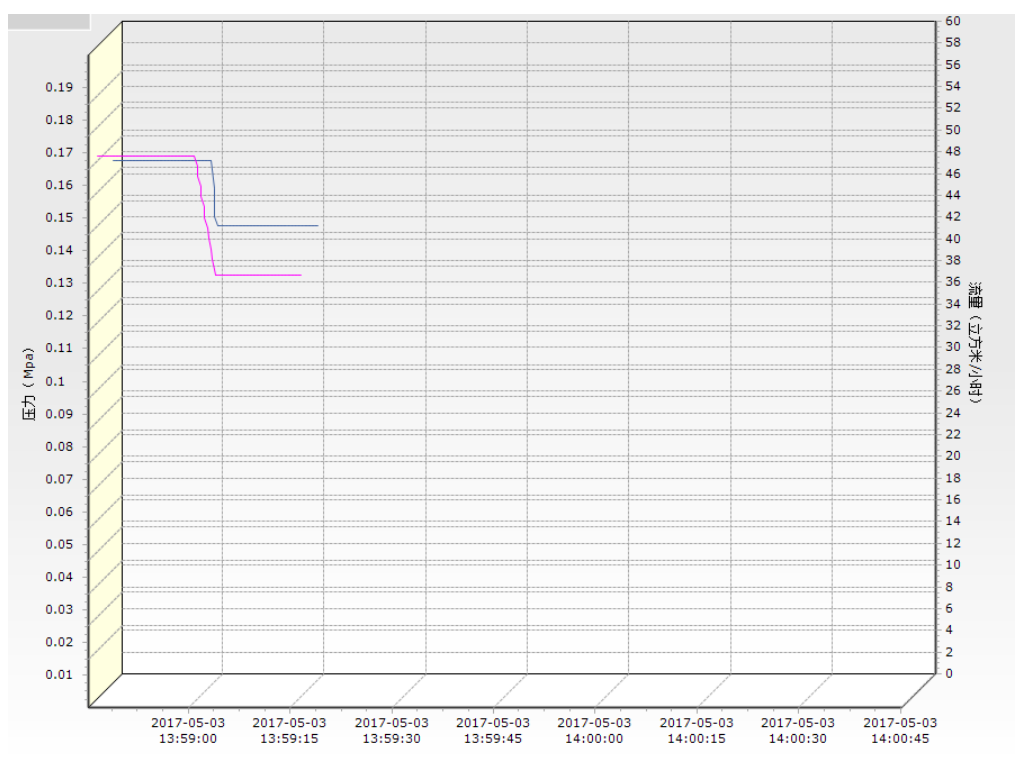

Figure 3-1 Common Wear Failure of Seawater Pump 
Figure 3-2 shows the process of seawater pump from normal operation to medium wear and then to reset. It can be seen from the graph that when the common fault of the seawater pump is reset, the fault will be eliminated immediately and the flow and pressure will return to normal condition. The countermeasure of breakdown: Start another group of seawater pumps to check and repair the breakdown seawater pumps.

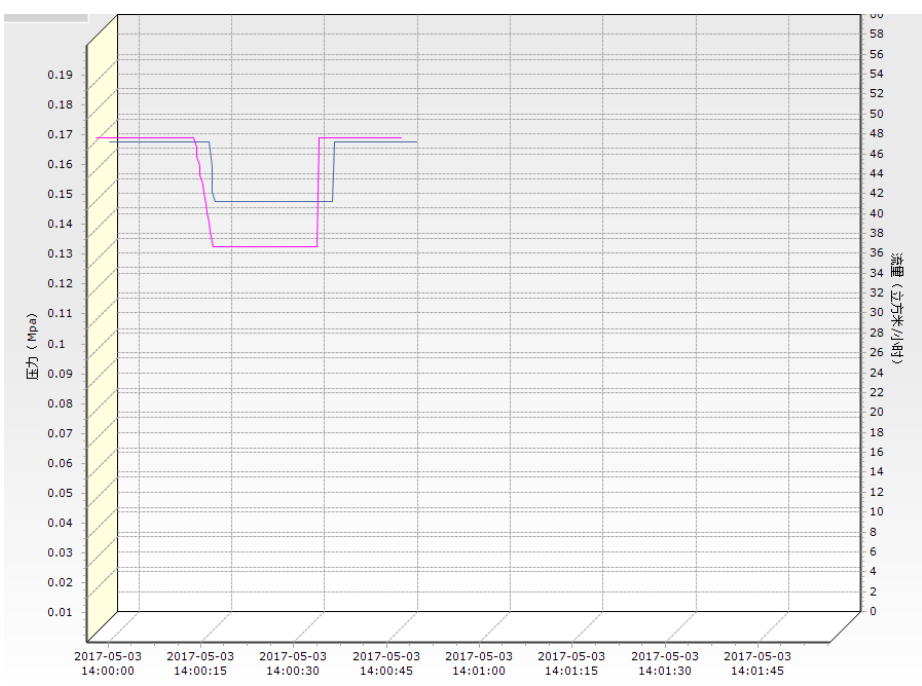

Fig. 3-2 Reposition of Common Wear Failure of Seawater Pump

\subsection{Blockage failure of submarine door}

Figure 3-3 shows the result of the blocking failure of the submarine door. It can be seen from the graph that the pressure difference before the submarine door filter is about $0.12 \mathrm{MPa}$, the pressure behind the filter is about $0.1 \mathrm{MPa}$ and the flow rate is about $50 \mathrm{~m} 3 / \mathrm{h}$ when the submarine door filter is in normal operation. After the blocking failure of the submarine door, the pressure difference before the submarine door filter rises to about $0.125 \mathrm{MPa}$, the pressure after the filter decreases to about $0.95 \mathrm{MPa}$, and the flow rate of the submarine door decreases to about $30 \mathrm{~m} 3 / \mathrm{h}$ in a straight line. If the fault will continue, the water temperature of the cylinder liner of the main engine will be selected as the measuring point because of the correlation of the mathematical model, and the water temperature will rise rapidly. If other relevant measuring points are selected, the data of other measuring points will also change..$^{[11]}$

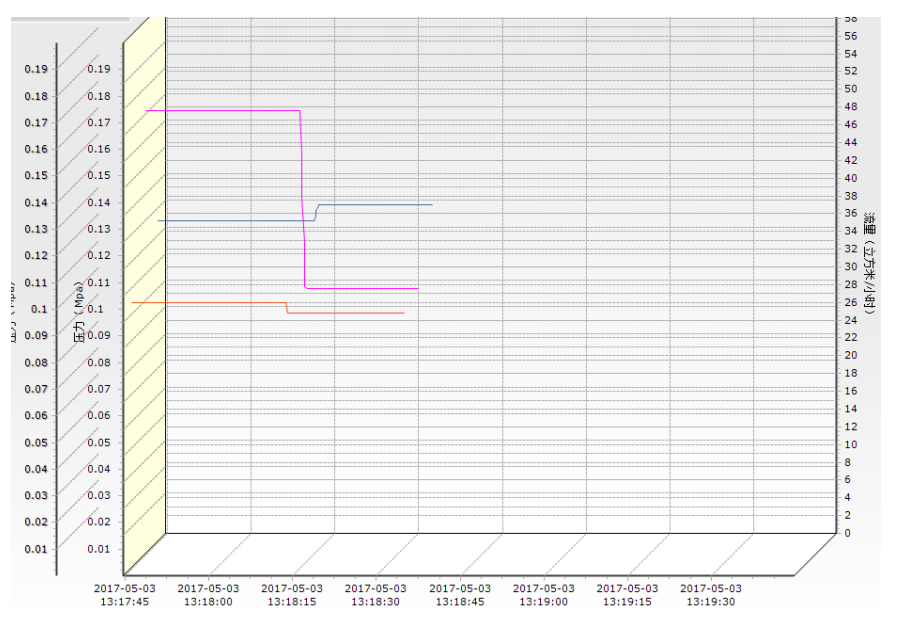

Figure 3-3 Seabed Gate Blockage Failure 
Figure 3-4 simulates the process of submarine door blockage from normal operation to reset after blockage failure. It can be seen from the graph that when the submarine door is blocked and reset, the fault is eliminated, and the flow and pressure of the submarine door filter before and after return to normal value. The countermeasure for blocking failure of submarine doors: timely inspection and cleaning of submarine doors, and opening another submarine door if conditions permit.

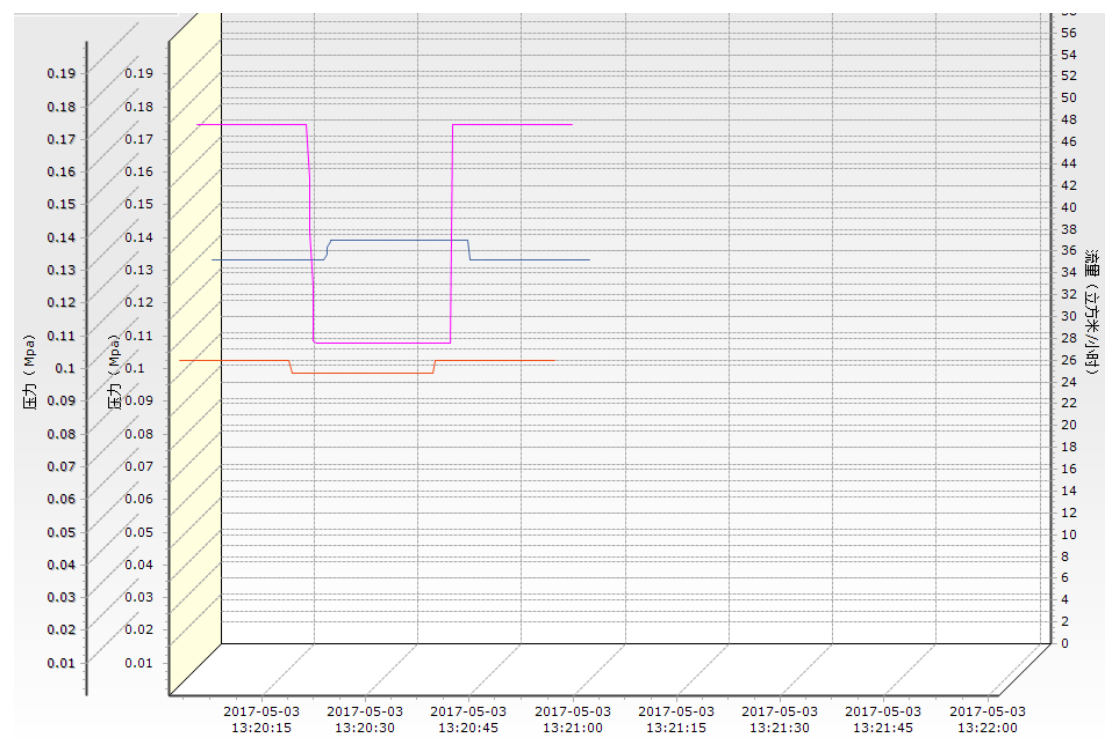

Figure 3-4 Seabed Gate Blockage Failure Reset

\section{CONCLUSION}

1) The mathematical model is established by the actual working parameters of the cooling water system of marine diesel engine, and the working state of the cooling water system of MTU20V956TB92 diesel engine is simulated by using the platform of Visual Studio 2012. The simulation results are close to the real ship, which shows the accuracy and rationality of the establishment process, and provides a basis for developing similar diesel engine fault simulation system. Definite reference value.

2) The simulation system breaks through the limitation of time and site. Through this system, the operators can be trained in ship cooling water system, and the training efficiency of the trainees can be improved, the training cost can be reduced, and the trainees'ability to judge the cause of the cooling water system failure can be improved.

\section{Reference documentation}

1. Wang Gongsheng. Working process simulation and fault simulation of marine low-speed twostroke diesel engine [D]. Dalian Maritime University, 2010.

2. Shang Qianming, Wang Ruihan, Chen Hui, Tang Xinfei. Application of multi-information fusion technology in fault diagnosis of marine diesel engine [J]. China Navigation, 2018 (03): 2631.

3. Wang Xiaomei. Development of monitoring and diagnosis system for marine diesel engine operation [D]. Shanghai Jiaotong University, 2011.

4. Zhang Qiaofen. Mathematical model of marine diesel propulsion system under multi-operating conditions and marine engine operation evaluation system [D]. Dalian Maritime University, 2016.

5. Yuan Yunfei. Research on Intelligent Fault Diagnosis Strategy of Marine Diesel Engine Lubrication System [D]. Jiangsu University of Science and Technology, 2015.

6. Huang Jialiang, Xie Gang. Thermal Fault Simulation of Marine Diesel Engine Based on BOOST [J]. Ship Science and Technology, 2015, 37 (1): 69-74.

7. Chen Jian. Mathematical modeling and Simulation of marine diesel engine governor [J]. Journal of System Simulation, 2018,30 (03): 937- 
942.

8. Qian Yuehua, Gong Dao, Zhu Jun. Development and application of real-time simulation model for marine low-speed diesel engine [J]. Marine Engineering, 2017, 39 (06): 20-23.

9. Xiao Wenjian, Li Yongke. Intelligent vehicle design based on incremental PID control algorithm [J]. Information technology, 2012, 36 (10): 125127.
10. Gu Linlin, Zhang Jundong. Simulation of diesel engine electronic governor based on fuzzy PID controller [J]. Journal of Dalian Maritime University, 2014, 40 (01): 57-60+65.

11. Ling Shuangming. Fuzzy PID adaptive control and Simulation of cooling water temperature of marine diesel engine cylinder liner [J]. Ship Science and Technology, 2017, 39 (12): 93-95.

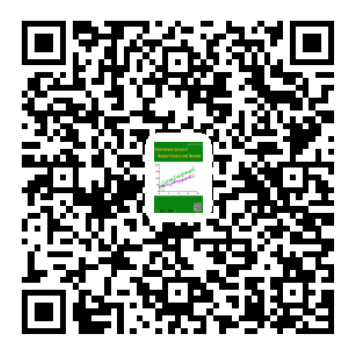

